\title{
Afferent loop syndrome treated by endoscopic ultrasound-guided gastrojejunos- tomy, using a lumen-apposing metal stent with an electrocautery-enhanced delivery system
}

Afferent loop syndrome is a complication that infrequently occurs after pancreaticoduodenectomy [1]. Complete obstruction occurs which leads to cholangitis, pancreatitis, perforation, and necrosis. In particular, patients with cancer recurrence cannot continue chemotherapy treatment, become debilitated, and may eventually die. Therefore, early and appropriate decompression treatment is needed.

This report describes endoscopic ultrasound (EUS)-guided gastrojejunostomy for treatment of afferent loop syndrome, using a lumen-apposing metal stent (LAMS) incorporated into an electrocautery-enhanced delivery system.

A 44-year-old man was admitted to our hospital with vomiting and abdominal pain; he had undergone pancreatoduodenostomy for pancreatic head cancer 11 months earlier. Computed tomography $(\mathrm{CT})$ revealed dilation of the afferent loop associated with a recurrence of cancer ( $\triangleright$ Fig. 1 ). First, multiple plastic stents were inserted by balloon-assisted enteroscopy (\$Fig.2) and his clinical condition improved. However, 1 month later he was admitted again with abdominal pain because of stent occlusion. CT revealed dilation of the afferent loop and intrahepatic bile duct ( Fig.3). We performed EUS-guided gastrojejunostomy with a LAMS incorporated into an electrocautery-enhanced delivery system (Hot AXIOS; Boston Scientific, Natick, Massachusetts, USA) (> Fig.4, - Video 1). CT on the following day showed improvement in the dilation of the afferent loop ( Fig.5). The patient showed resolution of clinical symptoms and received outpatient chemotherapy.

A previous report has demonstrated the usefulness of LAMS for transenteric drainage of pancreatic pseudocysts and the gallbladder [2]. Recently, EUS-guided transgastric access into the afferent limb with LAMS has been reported $[3,4]$.
The use of the Hot AXIOS system has some advantages compared with conventional LAMS, namely, avoidance of the need to exchange devices for stent placement, shortening of procedure time, prevention of leakage in the abdominal cavity, and prevention of separation of the digestive wall and afferent loop tract wall during the procedure.
Therefore, EUS-guided drainage with LAMS is a safe, easy-to-perform, and highly effective minimally invasive treatment modality for afferent loop syndrome.

Endoscopy_UCTN_Code_TTT_1AR_2AD

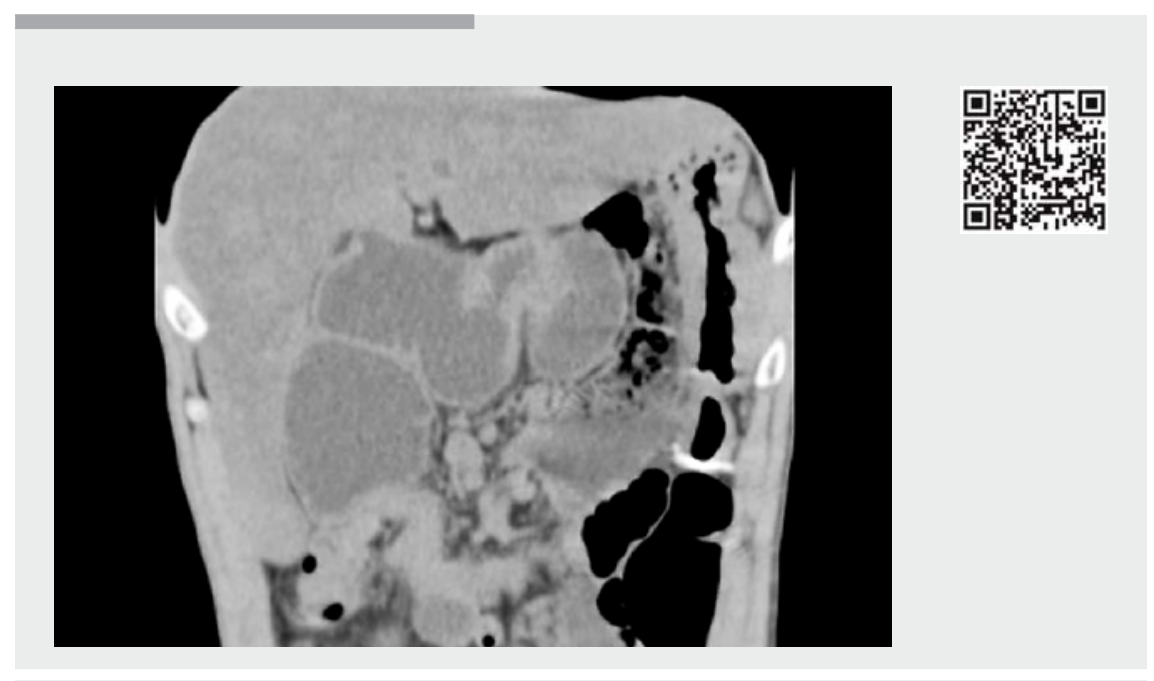

$\checkmark$ Video 1 Endoscopic ultrasound-guided gastrojejunostomy, using a lumen-apposing metal stent with an electrocautery-enhanced delivery system, for treatment of afferent loop syndrome.

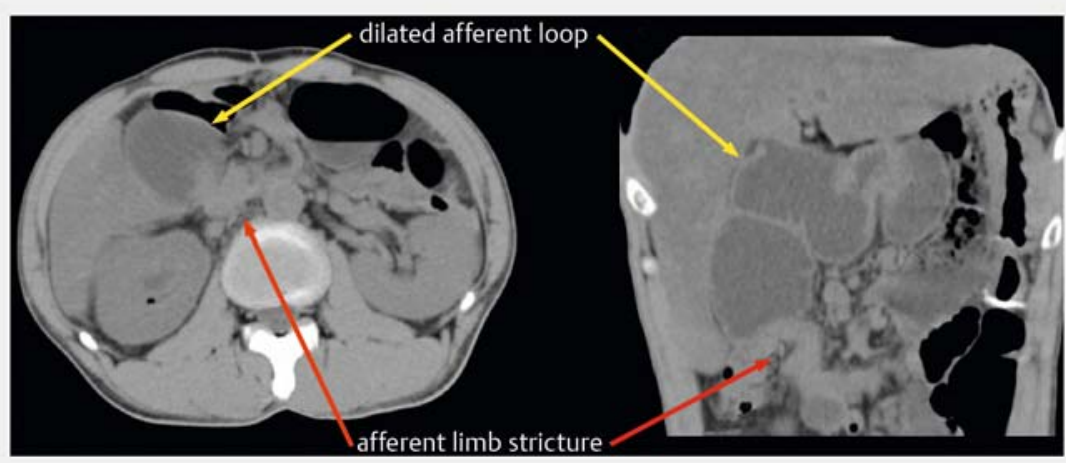

- Fig. 1 Computed tomography (CT) revealed dilation of the afferent loop associated with a recurrence of cancer, in a 44-year-old man who had undergone pancreatoduodenostomy for pancreatic head cancer 11 months previously. 

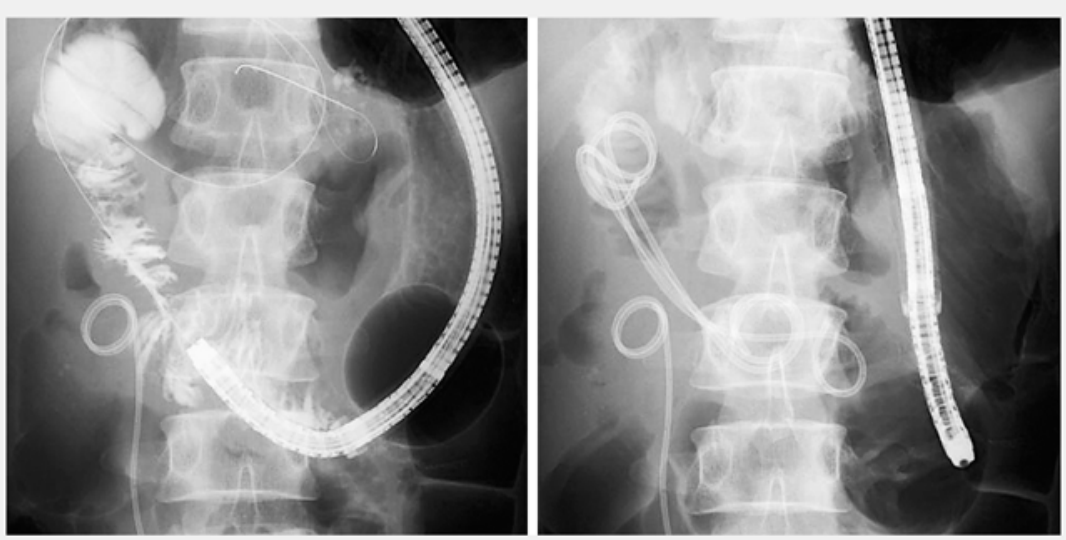

Fig.2 Multiple plastic stents were inserted by balloon-assisted enteroscopy.

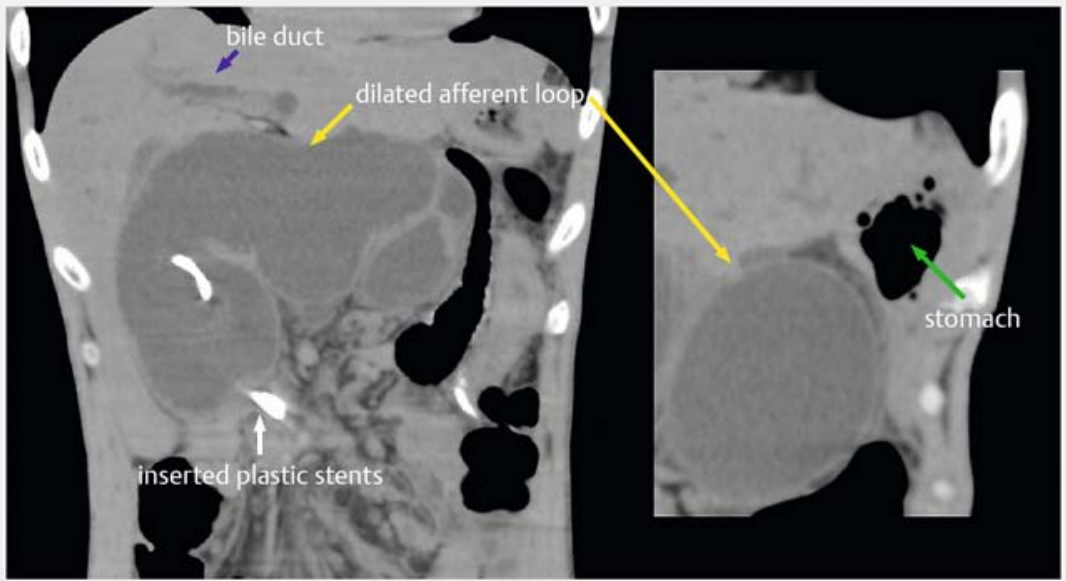

Fig. 3 CT revealed dilation of the afferent loop and intrahepatic bile duct.
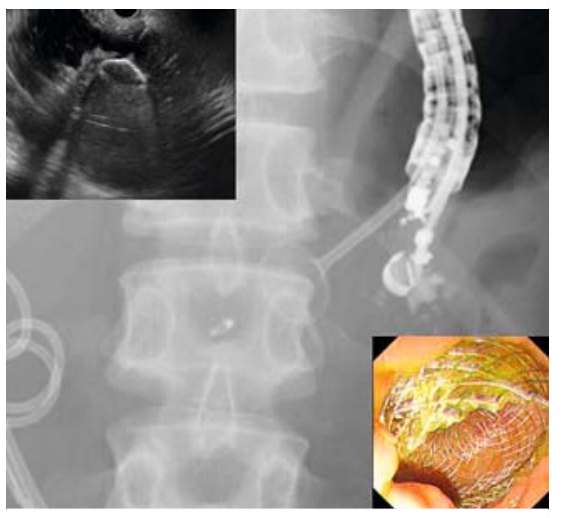

- Fig. 4 Endoscopic ultrasound (EUS)guided gastrojejunostomy was performed.

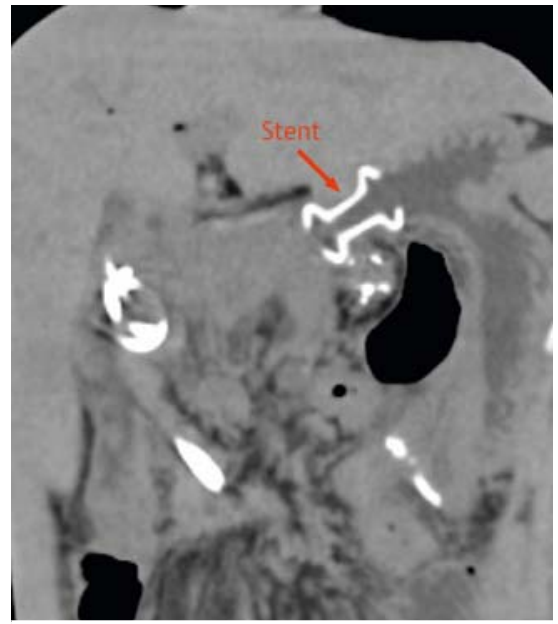

- Fig. 5 CTon postoperative day 1 showed improvement in the dilation of the afferent loop.
Competing interests

None

The Authors

Kenjiro Yamamoto ${ }^{1}$, Takayoshi Tsuchiya ${ }^{1}$, Reina Tanaka ${ }^{1}$, Honjo Mitsuyoshi' ${ }^{1}$, Shuntaro Mukai ${ }^{1}$, Yuichi Nagakawa ${ }^{2}$, Takao Itoi ${ }^{1}$

1 Department of Gastroenterology and Hepatology, Tokyo Medical University, Tokyo, Japan

2 Third Department of Surgery, Tokyo Medical University, Tokyo, Japan

\section{Corresponding author}

\section{Takao Itoi, MD, PhD}

Department of Gastroenterology and Hepatology, Tokyo Medical University, 6-7-1 Nishishinjuku, Shinjuku-ku,

Tokyo 160-0023, Japan

Fax: +81-3-53816654

itoi@tokyo-med.ac.jp 


\section{References}

[1] Wise SW. Case 24: afferent loop syndrome. Radiology 2000; 216: 142 - 145

[2] Itoi T, Binmoeller KF, Shah J et al. Clinical evaluation of a novel lumen-apposing metal stent for endosonography-guided pancreatic pseudocyst and gallbladder drainage (with videos). Gastrointest Endosc 2012; 75 : $870-876$

[3] Shah A, Khanna L, Sethi A. Treatment of afferent limb syndrome: novel approach with endoscopic ultrasound-guided creation of a gastrojejunostomy fistula and placement of lumen-apposing stent. Endoscopy 2015; 47 (Suppl. 01): E309-E310
[4] Taunk P, Cosgrove N, Loren DE et al. Endoscopic ultrasound-guided gastroenterostomy using a lumen-apposing self-expanding metal stent for decompression of afferent loop obstruction. Endoscopy 2015; 47 (Suppl. 01): E395-E396

\section{Bibliography}

DOI https://doi.org/10.1055/s-0043-115893

Published online: 10.8.2017

Endoscopy 2017; 49: E270-E272

(c) Georg Thieme Verlag KG

Stuttgart · New York

ISSN 0013-726X
ENDOSCOPY E-VIDEOS

https:/|eref.thieme.de/e-videos

回的 Endoscopy E-Videos is a free access online section, reporting 国: on interesting cases and new techniques in gastroenterological endoscopy. All papers include a high quality video and all contributions are freely accessible online.

This section has its own submission website at

https://mc.manuscriptcentral.com/e-videos 